\title{
REGIONAL DISTRIBUTION OF DYNORPHIN AND NEO- ENDORPHIN PEPTIDES IN RAT BRAIN, SPINAL CORD, AND PITUITARY ${ }^{1}$
}

\author{
RIC. I. CONE, ${ }^{*}$ ECKARD WEBER, JACK D. BARCHAS, $\ddagger$ AND AVRAM GOLDSTEIN ${ }^{* 2}$ \\ * Addiction Research Foundation, Palo Alto, California 94304 and $\ddagger$ Nancy Pritzker Laboratory for Behavioral Neurochemistry, \\ Department of Psychiatry, Stanford University, Stanford, California 94305
}

Received February 28, 1983; Revised April 29, 1983; Accepted May 5, 1983

\begin{abstract}
Five products of the dynorphin gene- $\alpha$-neo-endorphin, $\beta$-neo-endorphin, dynorphin $\mathrm{A}$, dynorphin A-(1-8), and dynorphin B-were measured in various regions of rat brain and in rat spinal cord and pituitary. Specific antisera were used, supplemented by gel permeation analysis and high performance liquid chromatography, confirming the presence of dynorphin-32, dynorphin $\mathrm{A}$, and dynorphin B in rat brain. In whole brain, $\alpha$-neo-endorphin, dynorphin A-(1-8), and dynorphin B are present in much greater amounts than $\beta$-neo-endorphin or dynorphin A. Although a general parallelism was found in the distribution of the five peptides, there were also noteworthy exceptions, suggesting that differential processing may occur.
\end{abstract}

The precursor sequence of the dynorphins and neoendorphins in porcine pituitary was recently deduced from mRNA, using cDNA hybridization technology (Kakidani et al., 1982). The $\mathrm{COOH}$-terminal region of the pro-dynorphin contains several opioid peptides, which have been isolated as separate products from mammalian neural tissues (Minamino et al., 1980, 1981; Goldstein et al., 1981; Kangawa et al., 1981; Fischli et al., 1982; Kilpatrick et al., 1982). These peptides (Fig. 1) are $\alpha$ - and $\beta$-neo-endorphin $(\alpha$-Neo, $\beta$-Neo), dynorphin $\mathrm{A}$ (Dyn A), dynorphin A-(1-8) (Dyn A-8), and dynorphin B (Dyn B). All contain a [Leu]enkephalin (Leu-enk) $\mathrm{NH}_{2}$-terminal sequence. Dyn $\mathrm{A}$ is the originally described 17-residue dynorphin (Goldstein et al., 1981). Dynorphin-32 (Dyn-32), recently isolated from porcine pituitary (Fischli et al., 1982), consists of $\mathrm{NH}_{2}$-terminal Dyn A followed by the "processing signal" $\mathrm{Lys}^{18}-\mathrm{Arg}^{19}$, and then by a novel 13-residuc Leu-enk-containing peptide (Dyn B) at the COOH-terminus. This peptide was also

\footnotetext{
${ }^{1}$ This investigation was supported by Grant DA-01207 from the National Institute on Drug Abuse to J. D. B., and by Grants DA-1199 from the National Institute on Druy Abuse, NS-18098 from the National Institutes of Health, and BNS-91-07237 from the National Science Foundation to A. G. E. W. is recipient of a Potamkin-Lerner Fellowship in the Neurosciences. We are grateful to Drs. M. Hunkapiller and Martha Bond for verifying the authenticity of the synthetic Dyn-32 and Dyn B-29, respectively, by sequence analysis. We thank Denise Hirai, Keiko Otsu, Madeline Rado, Asha Naidu, and Irene Inman for their excellent technical assistance.

${ }^{2}$ To whom correspondence should be sent.
}

sequenced by Kilpatrick et al. (1982) and called "rimorphin." Dynorphin B-29 (Dyn B-29), which contains Dyn $\mathrm{B}$, represents the deduced $\mathrm{COOH}$-terminal 29-residue sequence of pro-dynorphin; it has not yet been reported to be present in tissues.

In the processing model originally described for proinsulin (Docherty and Steiner, 1982), cleavage occurs immediately following a pair of basic amino acids, which are then removed sequentially by carboxypeptidase B. In pro-dynorphin, Lys-Arg must be recognized in preference to Arg-Arg or Arg-Lys in order to give rise to the observed neo-endorphin and dynorphin peptides, for otherwise Leu-enk would be the only opioid peptide obtained (cf. Fig. 1). Since proline peptide bonds are extremely resistant to peptidases, the expected neo-endorphin product is $\alpha$-Neo; if $\beta$-Neo has any telic significance, it would probably originate through the action of an unusual enzyme. Dyn A is flanked by Lys-Arg, and Dyn B-29 is the expected $\mathrm{COOH}$-terminal opioid peptide. Dyn A-8 and Dyn B are of interest because they require, in addition to the Lys-Arg processing, a special cleavage between an aliphatic neutral amino acid and arginine-a mechanism already noted for the vasopressin-neurophysin II precursor (Land et al., 1982). It is presently unknown whether any of the Leu-enk found in brain, spinal cord, or pituitary arises from pro-dynorphin.

To obtain more information about the processing of pro-dynorphin, we measured immunoreactive (ir) neoendorphin and dynorphin peptides in rat neural tissues and pituitary and characterized them by gel permeation 

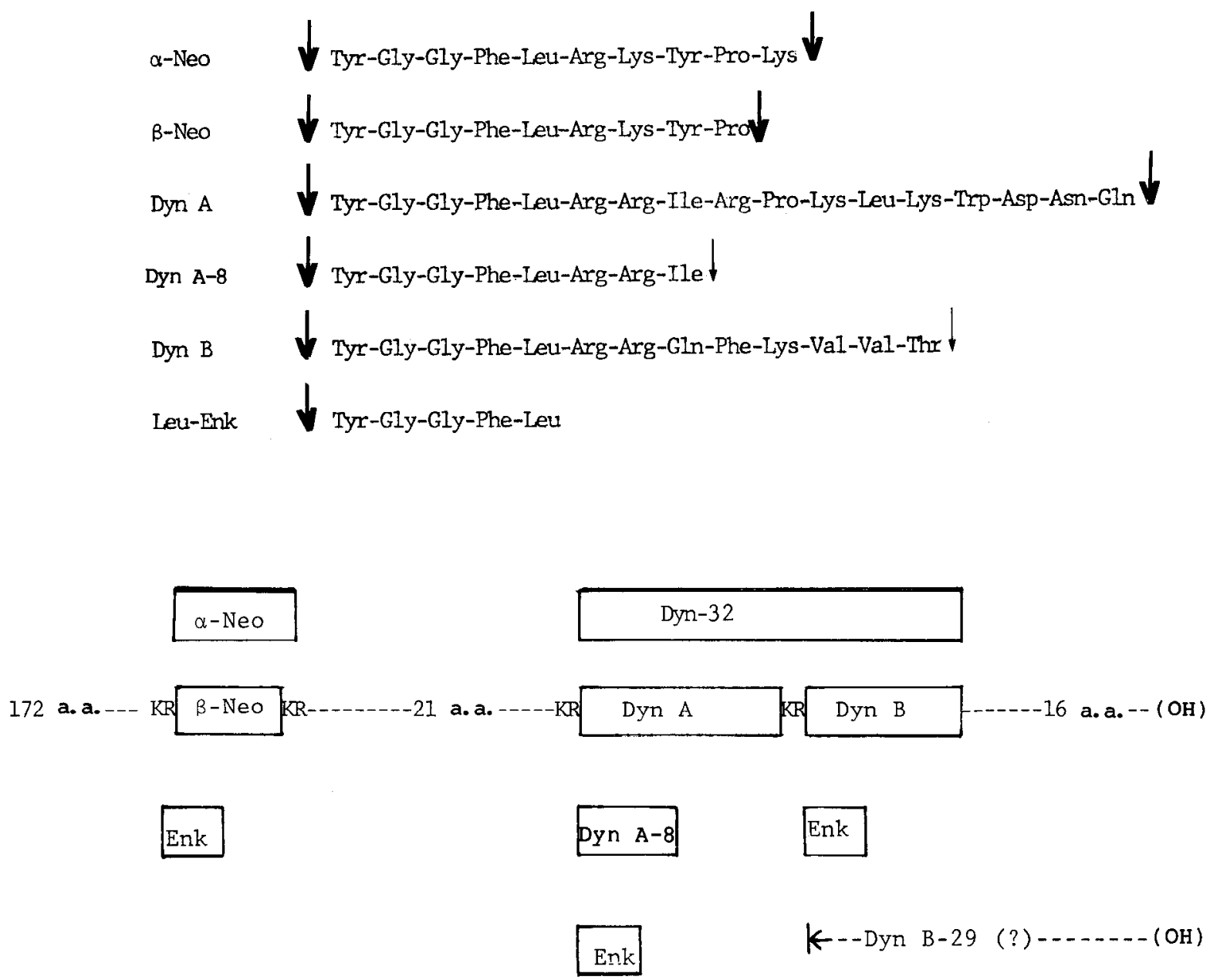

Figure 1. Opioid peptides contained in the deduced pro-dynorphin sequence. The sequence is from Kakidani et al. (1982). Bold arrows show where cleavages occur at Lys-Arg "processing signals," followed by removal of the two basic amino acids. The special case of $\alpha$ - and $\beta$-Neo is discussed in the text. Light arrows indicate clevages between a neutral aliphatic amino acid and arginine, giving rise to Dyn A-8 and Dyn B. The block diagram indicates various possible processing patterns.

and high performance liquid chromatography (HPLC). In this manner, stoichiometric relationships within the neo-endorphin and dynorphin families of peptides could be assessed.

\section{Materials and Methods}

Dyn A, Dyn B, Dyn A-8, $\alpha$-Neo, $\beta$-Neo, Dyn-32, and Dyn B-29 were synthesized by Peninsula Laboratories (San Carlos, CA). All peptides were demonstrated to be pure by HPLC. Sequences for Dyn-32 and Dyn B-29 were verified by Dr. M. Hunkapiller (California Institute of Technology, Pasadena, CA) and Dr. Martha Bond (DNAX Research Institute of Molecular and Cellular Biology, Inc., Palo Alto, CA), respectively.

Male Sprague-Dawley rats (300 to $350 \mathrm{gm}$ ) were obtained from Simonsen Laboratories (Gilroy, CA). Tissues from brain, spinal cord, and pituitary were removed immediately after decapitation, dissected on a chilled aluminum plate, weighed (except for pituitary), and quickly frozen between blocks of dry ice. The pituitary was dissected into an anterior lobe (AL) and a neurointermediate lobe (NIL), and pellet protein after extraction (see below) was determined by the method of Lowry et al. (1951). A value of $48 \mathrm{mg}$ of pellet protein/gm of wet weight, determined for rat brain in a previous study, was then used as a basis for estimating pituitary wet weights. Brain tissue was dissected into nine regions as described previously (Goldstein and Ghazarossian, 1980). This dissection differs slightly from that of Glowinski and Iversen (1966) in that the hypothalamic region is subdivided to yield an anterior hypothalamic block that includes the preoptic area, and a posterior hypothalamic block beginning at the level of the median eminence. In addition, cortical tissues rostral and caudal to the transverse cut made at the optic chiasm were extracted separately. Spinal cord tissue was a $1.5-\mathrm{cm}$ section measured from the point of decapitation. The 12 tissue samples from each animal were frozen within $15 \pm 2$ min (mean \pm SEM) of decapitation.

Frozen tissues were stored at $-70^{\circ} \mathrm{C}$ for less than 1 week, homogenized with a Tissumizer (Tekmar Co., Cincinnati, $\mathrm{OH}$ ) in $10 \mathrm{vol}$ (but not less than $1 \mathrm{ml}$ ) of $0.1 \mathrm{M}$ acetic acid at $100^{\circ} \mathrm{C}$, and incubated at this temperature for $30 \mathrm{~min}$. Following centrifugation $(13,000 \times \mathrm{g}, 20 \mathrm{~min}$, 
$\left.4^{\circ} \mathrm{C}\right)$ the supernatant solutions were assayed for ir- $\alpha$ Neo, ir- $\beta$-Neo, ir-Dyn A-8, ir-Dyn A, and ir-Dyn B.

Methods for the specific radioimmunoassay (RIA) of each peptide have been described. RIA for $\alpha$-Neo, $\beta$-Neo, and Dyn A-8 were performed as described by Weber et al. $(1982 \mathrm{a}, \mathrm{b})$, but modified to accommodate up to $50 \mu \mathrm{l}$ of $0.1 \mathrm{M}$ acetic acid, and peptide standards $(50 \mu \mathrm{l} /$ tube $)$ were in $0.1 \mathrm{M}$ acetic acid containing $0.1 \%$ bovine serum albumin (BSA) instead of RIA buffer. RIA for Dyn A (Ghazarossian et al., 1980) was modified to conform to the assay for Dyn B as described by Cone and Goldstein (1982). Synthetic peptide standards were prepared in either acidified methanol $(\mathrm{MeOH} / \mathrm{HCl}$; methanol and 0.1 $\mathrm{M} \mathrm{HCl}, 1: 1, \mathrm{v} / \mathrm{v}$ ) or $0.1 \mathrm{M}$ acetic acid containing $0.1 \%$ BSA and $0.1 \%$ Triton X-100 (TX). In no case did the modifications alter the sensitivity or slope of the standard curve. ${ }^{125}$ I-labeled tracers for each RIA were prepared as described previously (Ghazarossian et al., 1980; Cone and Goldstein, 1982; Weber et al., 1982a, b) and purified by HPLC.

The specificity of each antiserum has been described. Dyn A antiserum ("Lucia") (Ghazarossian et al., 1980), raised against dynorphin A-(1-13), does not cross-react with Dyn A-8, Leu-enk, $\alpha$-Neo, Dyn B, [Met]enkephalin, $\beta$-endorphin, $\alpha$-endorphin, or Dyn B-29. It recognizes dynorphin A-(1-13) or its methyl ester and Dyn A equally well, but the molar cross-reactivity of Dyn-32 is only 36\%. Dyn B antiserum ("13S") (Cone and Goldstein, 1982) does not recognize Dyn A, dynorphin A-(1-13), Leu-enk, $\alpha$-Neo, or $\beta$-endorphin. The cross-reactivity of Dyn-32 is $89 \%$, but that of Dyn B-29 is only $20 \%$. Thus, these two antisera can fully or partially recognize $\mathrm{COOH}$ terminal and $\mathrm{NH}_{2}$-terminal extensions of the peptides that were used as haptens. Antisera raised against Dyn $\mathrm{A}-8, \alpha-\mathrm{Neo}$, and $\beta$-Neo are directed against the $\mathrm{COOH}-$ terminal portion of each peptide and do not recognize $\mathrm{COOH}$-terminal extensions (Weber et al., 1982a, b). Dyn A-8 antiserum does not recognize Dyn A, Dynorphin-(113), Leu-enk, $\alpha$-Neo, or $\beta$-Neo; the cross-reactivity of dynorphin-(1-9) is only $1 \%$. The cross-reactivity of $\beta$ Neo with $\alpha$-Neo antiserum and of $\alpha$-Neo with $\beta$-Neo antiserum is less than $1 \%$. The neo-endorphin antisera do not recognize the enkephalins or dynorphins.

Adsorptive loss is a problem with all of the dynorphin and neo-endorphin peptides, as has been described for Dyn A (Ho et al., 1980) and Dyn B (Cone and Goldstein, 1982). Monoiodinated tracer peptides were placed in tubes in 1-ml volumes of $(a) 0.1 \mathrm{M}$ acetic acid alone; $(b)$ $0.1 \mathrm{M}$ acetic acid containing $0.1 \% \mathrm{BSA}$ and $0.1 \% \mathrm{TX} ;(c)$ $0.1 \mathrm{M}$ acetic acid containing a 1:20 dilution of brain extract prepared as described above; or $(d)$ sodium phosphate buffer, $150 \mathrm{mM}, \mathrm{pH} 7.4$, containing $0.1 \%$ BSA and $0.1 \%$ TX. After $20 \mathrm{~min}$ at $4^{\circ} \mathrm{C}, 0.5 \mathrm{ml}$ of each solution was transferred directly to another tube, which was placed in the gamma radiation counter. Recovery of radioactivity from acetic acid alone was only $63 \%, 49 \%$, $36 \%$, and $42 \%$ for $\alpha$-Neo, Dyn A, Dyn B, and Dyn A- 8 tracers, respectively. Recovery was greater than $92 \%$ from the other solutions. 'Therefore, dilution of tissue extracts prior to addition to the RIA incubation tube was avoided if possible and, when necessary, was carried out in the presence of $0.1 \% \mathrm{BSA}$ and $0.1 \% \mathrm{TX}$, or in $\mathrm{MeOH} /$ $\mathrm{HCl}$.
In order to assess recovery during extraction, $\alpha$-Neo, Dyn A, Dyn B, or Dyn A-8 tracer was mixed with representative brain samples immediately after homogenization. After incubation at $100^{\circ} \mathrm{C}$ and centrifugation, the recovery of radioactivity in the supernatant solutions was $100 \%, 82 \%, 111 \%$, and $106 \%$, respectively. Because of the very small amounts of synthetic peptide available, recovery controls were not carried out with Dyn-32 or Dyn B-29.

Extraction efficiencies for Dyn A and Dyn B were compared in a rat brain extract $(22 \mathrm{ml})$ prepared as described above. After centrifugation, the pellet was homogenized again in the same volume of acetic acid. The first extract contained $75 \%$ of the ir-Dyn A obtained in both extractions and $89 \%$ of the ir-Dyn B.

\section{Results \\ Characterization of peptide immunoreactivities}

The Dyn A and Dyn B antisera recognized several size classes of dynorphin-containing peptides. The size distribution profiles for ir-Dyn A and ir-Dyn B are given in Figure 2 for brain, NIL, and AL, based on Sephadex G50 chromatography. In brain, there were three apparent size classes, referred to here as 7-, 4-, and 2-kDal (kilodaltons). The ir-Dyn A and ir-Dyn B in both the 7- and 4-kDal peaks coincided exactly and were present in nearly equal amounts. The ir-Dyn A and ir-Dyn B in the 2-kDal peaks overlapped but did not coincide. The amount of 2 -kDal ir-Dyn B was approximately 4 -fold greater than that of ir-Dyn $\mathrm{A}$, and this difference accounted for $84 \%$ of the difference between total ir-Dyn B and total ir-Dyn A recovered from the column. The 2 -kDal peaks of immunoreactivity eluted in the same positions as synthetic Dyn A and Dyn B, respectively.

In NIL, only the $2-\mathrm{kDal}$ ir-Dyn A and ir-Dyn B were detectable, and the amounts of ir-Dyn $B$ recovered were approximately 3 -fold greater than those of ir-Dyn A. In anterior pituitary, all of the ir-Dyn A and ir-Dyn B was of the $7-\mathrm{kDal}$ size, and both immunoreactivities were present in nearly equal amounts.

Antisera directed against $\alpha$-Neo, $\beta$-Neo, and Dyn A-8 have been shown to recognize single size classes of peptide in rat brain, which co-elute on HPLC with the respective synthetic peptides (Weber et al., 1982a, b). The size distribution profiles for ir- $\alpha$-Neo and ir-Dyn A-8 were obtained in the same brain and NIL extracts described above, and it was confirmed that these immunoreactivities eluted as single peaks of the appropriate apparent molecular weights (data not presented).

The 2-kDal and 4-kDal peaks of ir-Dyn A and ir-Dyn $B$ were further characterized. The Sephadex fractions for the $2-\mathrm{kDal}$ material in rat brain were combined, concentrated, and characterized on an HPLC system designed for separation and identification of Dyn A and Dyn B. ir-Dyn A eluted in the same position as synthetic Dyn A, and ir-Dyn B eluted in the same position as synthetic Dyn B (Fig. 3). When a mixture of synthetic Dyn A and Dyn B was added to the Sephadex concentrate for co-elution on HPLC, single peaks were obtained (Fig. 3 , inset), confirming the presence of authentic Dyn A and Dyn B in rat brain. Essentially the same results were obtained for the 2-kDal ir-Dyn A and ir-Dyn B in rat NIL (not shown). 

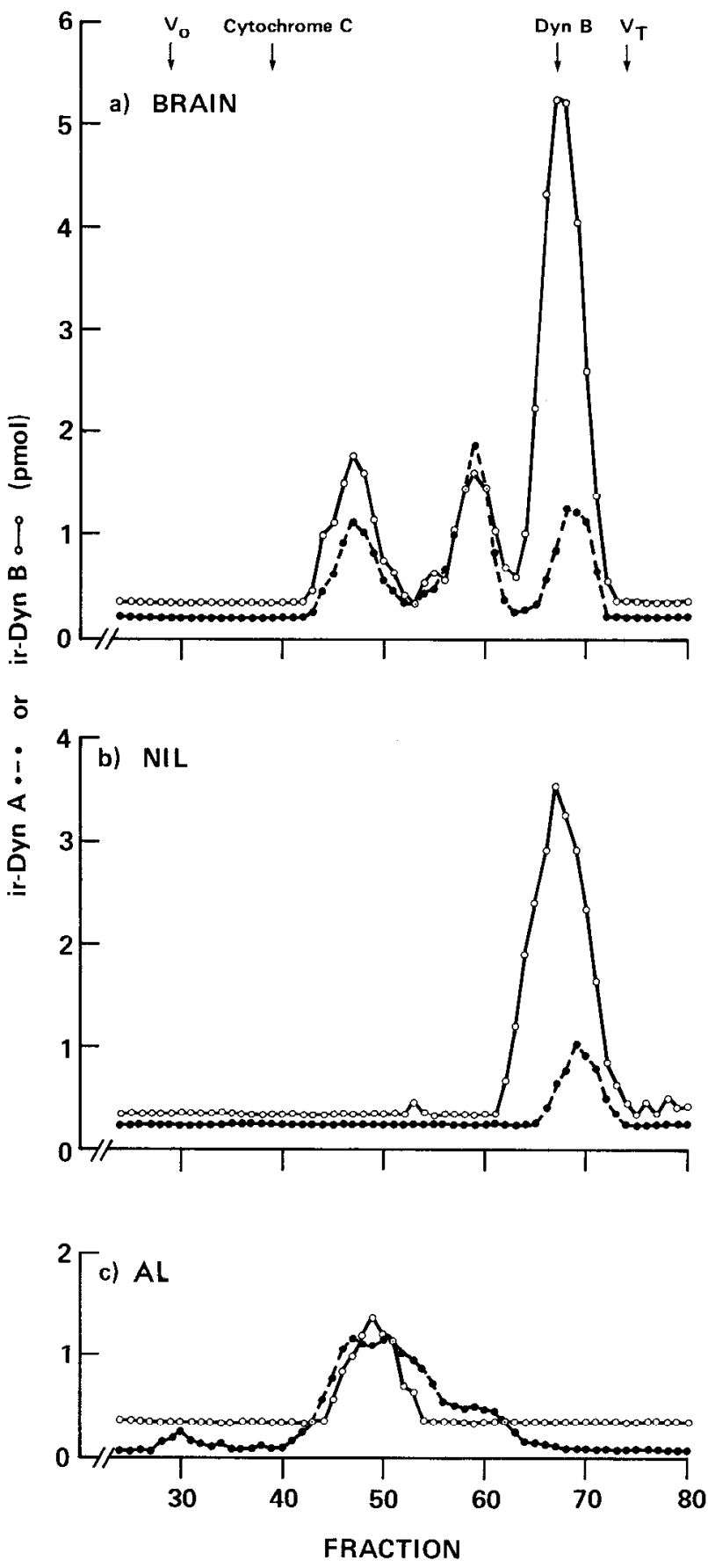

Figure 2. Gel permeation chromatography of rat brain and of rat pituitary NIL and AL. Extracts were prepared as described under "Materials and Methods" from three brains (60 $\mathrm{ml})$ or 12 pituitary glands $(3 \mathrm{ml})$. Brain extract was concentrated by lyophilizing and resuspending in $1 \mathrm{M}$ acetic acid (5.5 $\mathrm{ml}$ ). Then $3.5 \mathrm{ml}$ (brain) or $2.5 \mathrm{ml}$ (NIL, AL) of each extract were applied to a Sephadex G-50 fine column (Pharmacia; 90 $\times 1.5 \mathrm{~cm}$, elution solvent $0.1 \mathrm{M}$ acetic acid in $0.15 \mathrm{M} \mathrm{NaCl}$ with $0.1 \% \mathrm{TX})$ and eluted at 5 to $7 \mathrm{ml} / \mathrm{hr}$ at $4^{\circ} \mathrm{C}$. Fractions $(2 \mathrm{ml})$ were collected, and samples were removed for RIA. Elution profiles for ir-Dyn A (dashed line) and ir-Dyn B (solid line) are presented; ordinates are picomoles of immunoreactive peptide per fraction. Positions of markers were detcrmined scparately in the presence of brain tissue to avoid interference in the RIA. $V_{o}$, blue dextran; $V_{T}$, cobalt chloride. Cytochrome $c=12 \mathrm{kDal}$; synthetic Dyn $\mathrm{B}=1.6 \mathrm{kDal}$. Apparent molecular weights of the sample peaks were determined on a standard plot of $\log M_{\mathrm{r}}$ against elution volume expressed as $K_{\mathrm{av}}\left(V /\left(V_{T^{-}} V_{o}\right)\right)$, using
The 4-kDal Sephadex concentrate from rat brain was characterized using an HPLC system in which Dyn-32 and Dyn B-29 were well separated. ir-Dyn A and ir-Dyn $B$ eluted in exactly the same position, which coincided with that of synthetic Dyn-32 (Fig. 4). A very small amount of ir-Dyn $B$ was detectable in the position of Dyn B-29. When synthetic Dyn-32 was added to the Sephadex concentrate for co-elution on HPLC, a single peak containing both immunoreactivities was obtained (Fig. 4, inset), confirming the presence of authentic Dyn32 in rat brain. The $7-\mathrm{kDal}$ ir-Dyn $\mathrm{A}$ and ir-Dyn $\mathrm{B}$ in rat brain and $A L$ were not characterized on HPLC in this study.

Quantitative comparisons of immunoreactive peptides by regions. Tissue concentrations of immunoreactive $\alpha$ -

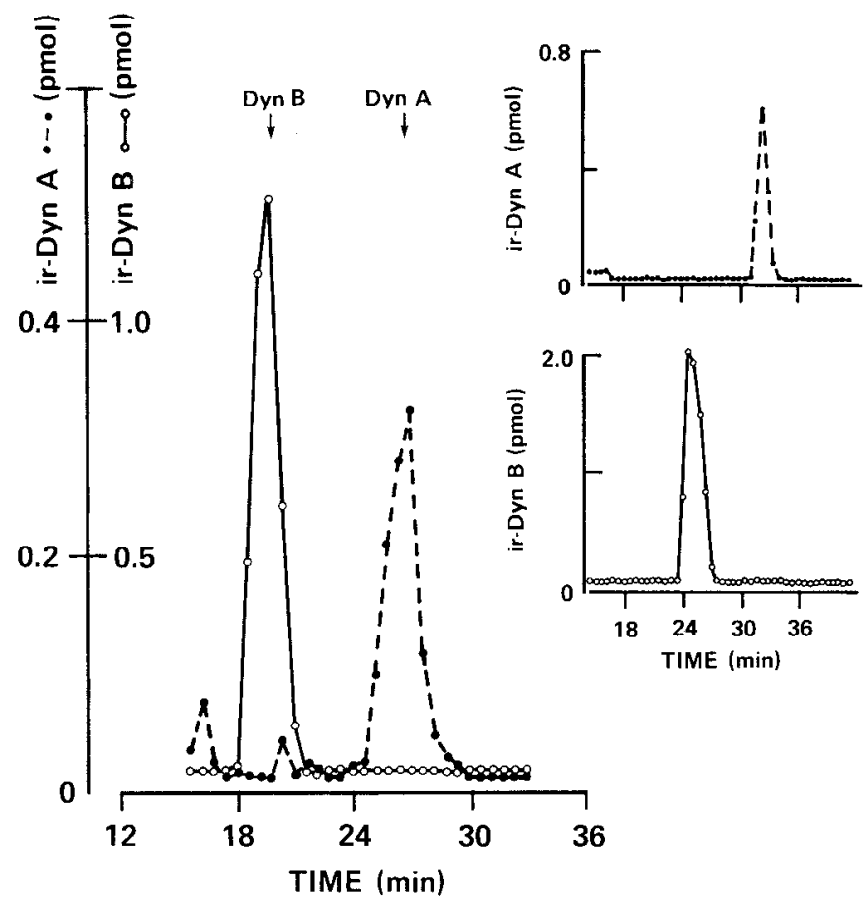

Figure 3. Reversed phase HPLC of rat brain 2-kDal peak. A Waters Associates system was used with a $\mu$ Bondapak $\mathrm{C}_{18}$ column $(3.9 \times 300 \mathrm{~mm})$, linear gradient 22 to $32 \% \mathrm{CH}_{3} \mathrm{CN}$ in $5 \mathrm{mM}$ trifluoroacetic acid $(45 \mathrm{~min}, 1.0 \mathrm{ml} / \mathrm{min}, 0.6-\mathrm{min}$ fractions). Material applied was $500 \mu \mathrm{l}$ of a $\mathrm{MeOH} / \mathrm{HCl}$ concentrate from fractions 67 to 70 (see Fig. 2) containing 0.9 pmol ir-Dyn $\mathrm{A}$ and $3.4 \mathrm{pmol}$ ir-Dyn B. The experiment in the inset contained the same amount of brain material with a mixture of synthetic Dyn A (2.0 pmol, upper) and Dyn B (5 pmol, lower) added as internal standards. Elution profiles for ir-Dyn A (dashed line) and ir-Dyn B (solid line) are presented relative to retention time on the column. Retention times of synthetic Dyn A and Dyn B (arrows) were determined by absorbance in a separate run. The difference in elution times between runs is due to flow rate variations caused by a defective pump. Recoveries for irDyn $\mathrm{A}$ and ir-Dyn B were $106 \%$ and $98 \%$, respectively, of the amounts present in the $\mathrm{MeOH} / \mathrm{HCl}$ concentrate.

cytochrome $c$, Dyn-32, and Dyn A or Dyn B as markers. Recoveries were as follows. Brain: $89 \%$ of ir-Dyn A and $74 \%$ of ir-Dyn B was recovered following lyophilization, and $72 \%$ of both immunoreactivities applied to the column were recovered in the fractions. NIL: $33 \%$ of ir-Dyn A and $57 \%$ of ir-Dyn B. AL: $38 \%$ of ir-Dyn A and $36 \%$ of ir-Dyn B. Solid circles (dashed line), ir-Dyn A; open circles (solid line), ir-Dyn B. 


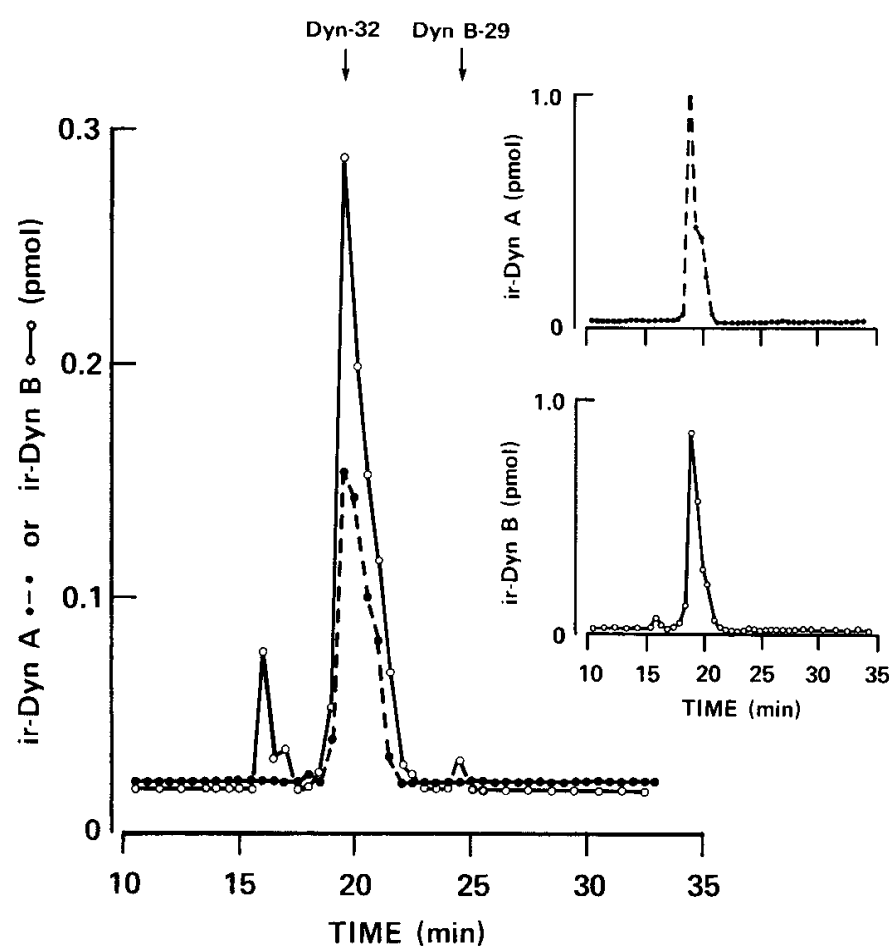

Figure 4. Reversed phase HPLC of rat brain 4-kDal peak. For details, see Figure 3 legend. A linear gradient was run from 25 to $55 \% \mathrm{CH}_{3} \mathrm{CN}$ in $5 \mathrm{mM}$ trifluoroacetic acid $(40 \mathrm{~min}, 1.5 \mathrm{ml} /$ $\mathrm{min}, 0.5-\mathrm{min}$ fractions). Material applied was $250 \mu \mathrm{l}$ of a $\mathrm{MeOH} / \mathrm{HCl}$ concentrate from fractions 58 to 60 (see Fig. 2) containing $0.72 \mathrm{pmol}$ immunoreactive equivalent (average of ir-Dyn A and ir-Dyn B). The experiment in the inset contained the same amount of brain material with synthetic Dyn-32 (1.8 pmol) added as internal standard. Elution profiles for ir-Dyn $\mathrm{A}$ (dashed line) and ir-Dyn B (solid line) are presented relative to retention time on the column. Retention times of synthetic Dyn-32 and Dyn B-29 (arrows) were determined by absorbance in a separate run. Flow rate variations between runs were recognized and adjusted for by reference to a characteristic absorbance pattern ("fingerprint") of the brain extract material. Recoveries for ir-Dyn A and ir-Dyn B were $61 \%$ and $107 \%$, respectively, of the amounts present in the $\mathrm{MeOH} / \mathrm{HCl}$ concentrate. The lower recovery of ir-Dyn A is consistent with the observed lower molar cross-reactivity of synthetic Dyn-32 with Dyn $\mathrm{A}$ antiserum (see the text).

Neo, $\beta$-Neo Dyn A-8, Dyn A, and Dyn B were determined in the nine brain regions, spinal cord, and pituitary NIL and AL. The brain regions are ranked, in Table I, according to concentration of total ir- $\alpha$-Neo. For all five peptides, highest brain concentrations were in anterior hypothalamus. Accordingly, in Table II, the concentration in each region is expressed as a percentage of that found in anterior hypothalamus.

A general parallelism is evident for all of the peptides. Concentrations were very high in hypothalamus, low in cortex, and extremely low in cerebellum. Concentrations in NIL were 20 to 50 times those in anterior hypothalamus, with ir- $\beta$-Neo present in relatively higher concentration. Across brain regions and in spinal cord there was a remarkable similarity between the concentrations of ir- $\alpha$-Neo and ir-Dyn A-8, as reported previously (Weber et al., 1982a); the ratio of the former to the latter was $1.05 \pm .003$ (mean $\pm \mathrm{SEM}, N=54$ ). Exceptions to the parallelism are most readily noted in Table II: $(a)$ in posterior hypothalamus, ir-dyn A was relatively higher than the other peptides; $(b)$ in striatum, ir- $\alpha$-Neo and irdyn A-8 were relatively high, whereas ir- $\beta-\mathrm{Neo}$ and irdyn A were relatively low; $(c)$ in midbrain, ir $-\alpha$-Neo and ir-dyn A-8 were relatively high, whereas ir-dyn A was relatively low; $(d)$ in hippocampus, ir-dyn $\mathrm{A}$ was relatively high, whereas ir- $\beta$-Neo was very low; $(e)$ in spinal cord, ir-Dyn A was relatively high, whereas ir- $\alpha$-Neo and ir-Dyn A-8 were relatively low. The results for ir- $\alpha-\mathrm{Neo}$ and ir- $\beta-\mathrm{Neo}$ are similar to those reported recently by Weber et al. (1982b) and Kitamura et al. (1982). It should be noted that our analysis does not compare actual concentrations of the peptides within a single region, but rather the concentration of each relative to its concentration in anterior hypothalamus.

Values for whole brain were obtained by summation of the nine regional results. These values for ir- $\alpha-\mathrm{Neo}$, ir- $\beta$-Neo, and ir-Dyn A-8 presumably represent the authentic peptides, as already noted, whereas comparable data for ir-Dyn A and ir-Dyn B represent a mixture of molecular sizes. By applying the gel permeation results, it was possible to estimate authentic Dyn A and Dyn B according to the fraction of total immunoreactivity in the 2-kDal peak (Fig. 2). These data are given in Table III. Authentic $\alpha$-Neo, Dyn A-8, and Dyn B were present in roughly similar amounts, whereas there was much less $\beta$-Neo and Dyn A.

In pituitary NIL, all five peptide immunoreactivities consisted entirely of single size classes (Fig. 2; Weber et al., 1982a, b), and the concentrations were several hundred times greater than in whole brain (cf. Table II). In pituitary $\mathrm{AL}$, concentrations of ir $-\alpha-\mathrm{Neo}$ and ir $-\beta-\mathrm{Neo}$ were 3- to 4-fold greater than in whole brain. ir-Dyn A and ir-Dyn B were exclusively of the 7-kDal size class and at 10 to 20 times their concentrations in whole brain. Because of the higher detection limit in the Dyn A-8 RIA, the relative content of Dyn A-8 in pituitary AL could not be assessed.

\section{Discussion}

We have shown here that $\alpha-\mathrm{Neo}, \beta-\mathrm{Neo}$, Dyn A-8, Dyn $\mathrm{A}$, and Dyn $\mathrm{B}$ are all present in rat brain, as well as Dyn32 (which contains both Dyn A and Dyn B). Identification of the first three rests upon the extremely high specificity of the antisera used. Identification of the last three rests upon gel permeation profiles and co-elution with synthetic peptides on HPLC. A 7 -kDal peak containing ir-Dyn A and ir-Dyn B is also present in brain, and it comprises the solitary form of these immunoreactivities in pituitary AL; it is presumably the same as the 6 -kDal material reported by Seizinger et al. (1981). It could possibly represent a 48-residue peptide composed of Dyn-32 with Dyn B-29 instead of Dyn B at its carboxyl terminus; or alternatively, it could be an $\mathrm{NH}_{2}$-terminally extended form of Dyn-32.

Interestingly, pro-dynorphin gives rise, in brain, spinal cord, and pituitary NIL, to a greater variety of opioid peptides than would be expected from cleavages at the recognized Lys-Arg "processing signals" (see Fig. 1). $\alpha$ Neo, Dyn A-8, and Dyn B have in common a cleavage to the left of a single arginine residue, perhaps accomplished 
TABLE I

Distribution of immunoreactive peptides by region

Data are means \pm SEM, expressed as immunoreactive peptide equivalents for six male Sprague-Dawley rats (mean body weight $338 \pm 10$ gm). All values are rounded to two significant figures. Spinal cord is a $1.5-\mathrm{cm}$ section measured from the point of decapitation. For extraction procedure, see "Materials and Methods."

\begin{tabular}{|c|c|c|c|c|c|c|}
\hline & \multirow{2}{*}{ Tissue } & \multicolumn{5}{|c|}{ Immunoreactive Peptide Concentration } \\
\hline & & $\alpha$-Neo & $\beta$-Neo & Dyn A-8 & Dyn $A^{a}$ & Dyn $B^{a}$ \\
\hline & $m g$ & & & $\mathrm{pmol} / \mathrm{gm}$ & & \\
\hline \multicolumn{7}{|l|}{ Brain } \\
\hline Posterior hypothalamus & $26 \pm 1$ & $64 \pm 5.6$ & $33 \pm 3.1$ & $65 \pm 8.8$ & $48 \pm 4.9$ & $82 \pm 8.2$ \\
\hline Striatum & $140 \pm 9$ & $34 \pm 1.7$ & $4.3 \pm 0.9$ & $32 \pm 1.6$ & $9.7 \pm 1.0$ & $29 \pm 3.2$ \\
\hline Midbrain & $230 \pm 10$ & $33 \pm 1.7$ & $10 \pm 0.1$ & $30 \pm 1.6$ & $8.5 \pm 0.5$ & $29 \pm 0.9$ \\
\hline Cortex B & $480 \pm 12$ & $12 \pm 0.6$ & $3.3 \pm 0.3$ & $11 \pm 0.3$ & $8.8 \pm 0.4^{b}$ & $17 \pm 0.7$ \\
\hline Cortex C & $330 \pm 16$ & $12 \pm 0.6$ & $3.4 \pm 0.1^{b}$ & $12 \pm 0.7$ & $5.8 \pm 0.2$ & $14 \pm 0.6^{b}$ \\
\hline Cerebellum & $290 \pm 8$ & $2.2 \pm 0.2^{b}$ & $<1$ & $<4$ & $0.7 \pm 0.1^{b}$ & $1.4 \pm 0.2$ \\
\hline Spinal cord & $160 \pm 3$ & $13 \pm 0.4$ & $8.9 \pm 0.6$ & $12 \pm 0.3$ & $15 \pm 0.3$ & $19 \pm 0.9$ \\
\hline \multicolumn{7}{|l|}{ Pituitary } \\
\hline
\end{tabular}

${ }^{a}$ Dyn A and Dyn B immunoreactivities are composites of the contributions from authentic Dyn A and Dyn B and the larger forms (Dyn-32 and 7 -kDal dynorphin). See also Figure $2 A$ and Table III.

${ }^{b}$ Based on five of the six animals, one sample having been lost in the assay.

TABLE II

Immunoreactive peptides by region, relative to concentration in anterior hypothalamus ${ }^{a}$

\begin{tabular}{lrrrrr}
\hline & \multicolumn{5}{c}{$\begin{array}{l}\text { Immunoreactive Peptide Concentrations Relative to } \\
\text { Anterior Hypothalamus (\%) }\end{array}$} \\
\cline { 2 - 6 } & $\alpha$-Neo & $\beta$-Neo & Dyn A-8 & Dyn A & Dyn B \\
\hline Brain & & & & & \\
$\quad$ Anterior & 100 & 100 & 100 & 100 & 100 \\
$\quad$ hypothalamus & & & & & \\
Posterior & 70 & 79 & 71 & 98 & 73 \\
$\quad$ hypothalamus & & & & & \\
Striatum & 38 & 10 & 35 & 20 & 26 \\
Midbrain & 37 & 25 & 33 & 17 & 26 \\
Hippocampus & 20 & 10 & 17 & 34 & 22 \\
Medulla-pons & 18 & 30 & 19 & 26 & 20 \\
Cortex B & 13 & 8.0 & 12 & 18 & 15 \\
Cortex C & 13 & 8.0 & 13 & 12 & 13 \\
Cerebellum & 2 & $<2.4$ & $<4.3$ & 1.4 & 1.3 \\
Spinal cord & 14 & 22 & 13 & 30 & 17 \\
Pituitary & & & & & \\
NIL & 2200 & 5100 & 1800 & 2500 & 2900 \\
AL & 55 & 68 & $<78$ & 360 & 160 \\
\hline
\end{tabular}

${ }^{a}$ See legend to Table I.

by a trypsin-like enzyme followed by carboxypeptidase B. Such an enzyme would have interesting specificity, for it would have to act at arginine-9 of Dyn A and arginine-14 of Dyn B in preference to the several other arginine residues in the neo-endorphin and dynorphin sequences.

The present data differ from those of Weber et al. (1982a) in showing considerably lower ratios of ir-Dyn A-8 to ir-Dyn A. The difference is probably accounted for by poorer extraction of the larger forms (Dyn-32 and 7-kDal dynorphin) into acid-acetone in the earlier study than into the $0.1 \mathrm{M}$ hot acetic acid used in the present work. This interpretation is supported by the data of
TABLE III

Concentrations of the immunoreactive peptides in whole brain

Whole brain estimates of immunoreactive peptide concentrations are based upon summations of the nine regional values for each animal (Table I). Spinal cord was not included. Mean brain weight was 2000 $\pm 35 \mathrm{mg}$ for six animals. Means \pm SEM for $\beta$-Neo and Dyn A-8 were computed on the assumption that the concentration in cerebellum was at the detection limit of the RIA. "Authentic" peptide concentrations refer to peptides of the 1 - to 2 -kDal size class. RIA for $\alpha$-Neo, $\beta$-Neo, and Dyn A-8 does not measure extended or truncated forms. Data for Dyn A and Dyn B have been corrected according to Figure 2, to eliminate immunoreactive peptides of larger size classes.

\begin{tabular}{lccccc}
\hline & $\alpha$-Neo & $\beta-$ Neo & Dyn A-8 & Dyn A & Dyn B \\
\hline $\begin{array}{l}\text { Immunoreactive } \\
\begin{array}{c}\text { peptide con- } \\
\text { centration }\end{array}\end{array}$ & $18 \pm 0.3$ & $6.3 \pm 0.1^{a}$ & $17 \pm 0.4$ & $9.7 \pm 0.1^{a}$ & $20 \pm 0.4^{a}$ \\
$\begin{array}{c}\text { "Authentic" } \\
\text { peptide con- } \\
\text { centration }\end{array}$ & 18 & 6.3 & 17 & 2.8 & 12 \\
\hline
\end{tabular}

${ }^{a}$ See Footnote $b$ to Table I.

Table III, showing that for whole brain the ratio or irDyn A-8 to ir-Dyn A changes from 1.8 to 6.1 when the contribution of the larger peptides to the total immunoreactivity is removed. This correction does not depend upon knowledge of the absolute amounts of the larger peptides, which cannot be determined without more information about recoveries. The whole brain ratio found by Weber et al. (1982a) was approximately 6 . We did not carry out gel permeation analyses for the discrete brain regions, but if the whole brain correction is applied to each region, the regional discrepancies in the ratio also largely disappear. We did not make such corrections, however, because they would require the unproved assumption that the relative amounts of the different size classes of ir-Dyn A are the same in each region as in whole brain. 
Some products of pro-dynorphin are mutually exclusive in the sense that they contain a common sequence. For example, one molecule of pro-dynorphin could yield $\alpha$-Neo or $\beta$-Neo but not both; the same is true for Dyn A and Dyn A-8, as well as for Dyn B-29 (if it exists) and Dyn B. It is of interest, therefore, that at least in some regions there seems to be a reciprocal relationship between such muttially exclusive peptides. For example, the relative concentration of Dyn A-8 is much lower in hippocampus than in midbrain, whereas the converse is true of Dyn A. Another example is in pituitary NIL, where all measured immunoreactivities represent peptides of the 1- to $2-\mathrm{kDal}$ size class. Here (cf. Table I) the sum of Dyn A-8 and Dyn A is equal to Dyn B, and the sum of $\alpha$-Neo and $\beta$-Neo is very nearly the same. This pattern suggests that most of the $\mathrm{COOH}$-terminal sequence of the precursor may be processed to Dyn B, with little if any Dyn B-29 formed.

Overall, the pattern of concentrations of the immunoreactive peptides varies from region to region. If one assumes that the peptides are present in approximate proportion to their relative rates of production (i.e., that differential degradation, diffusion, or storage has not distorted the patterns), it would follow that processing may take different pathways in different regions. Although all products of pro-dynorphin are selective ligands of the $\kappa$-opioid receptor (I. F. James, W. Fischli, and $\mathrm{A}$. Goldstein, manuscript in preparation), they have different degrees of selectivity, different potencies, and probably different metabolic stabilities in brain. Differential processing might therefore be a mechanism for regulating function in the dynorphin ( $\kappa$-opioid) system.

\section{References}

Cone, R. I., and A. Goldstein (1982) A specific radioimmunoassay for the opioid peptide dynorphin $B$ in neural tissues. Neuropeptides 3: 97-106.

Docherty, K., and D. F. Steiner (1982) Post-translational proteolysis in polypeptide hormone biosynthesis. Annu. Rev. Physiol. 44: 625-638.

Fischli, W., A. Goldstein, M. W. Hunkapiller, and L. E. Hood (1982) Isolation and amino acid sequence analysis of a 4,000dalton dynorphin from porcine pituitary. Proc. Natl. Acad. Sci. U. S. A. 79: 5435-5437.

Ghazarossian, V. E., C. Chavkin, and A. Goldstein (1980) A specific radioimmunoassay for the novel opioid peptide $\mathrm{dy}$ norphin. Life Sci. 27: 75-86.

Glowinski, J., and L. L. Iversen (1966) Regional studies of catecholamines in the rat brain. I. The disposition of $\left[{ }^{3} \mathrm{H}\right]$ norepinephrine, $\left[{ }^{3} \mathrm{H}\right]$ dopamine and $\left[{ }^{3} \mathrm{H}\right]$ dopa in various re- gions of the brain. J. Neurochem. 13: 655-669.

Goldstein, A., and V. E. Ghazarossian (1980) Immunoreactive dynorphin in pituitary and brain. Proc. Natl. Acad. Sci. U. S. A. 77: 6207-6210.

Goldstein, A., W. Fischli, L. I. Lowney, M. Hunkapiller, and L. Hood (1981) Porcine pituitary dynorphin: Complete amino acid sequence of the biologically active heptadecapeptide. Proc. Natl. Acad. Sci. U. S. A. 78: 7219-7223.

Ho, W. K. K., B. M. Cox, C. Chavkin, and A. Goldstein (1980) Opioid peptide dynorphin-(1-13): Adsorptive losses and potency estimates. Neuropeptides 1: 143-152.

Kakidani, H., Y. Furutani, H. Takahashi, M. Noda, Y. Morimoto, T. Hirose, M. Asai, S. Inayama, S. Nakanishi, and S. Numa (1982) Cloning and sequence analysis of cDNA for porcine $\beta$-neo-endorphin/dynorphin precursor. Nature 298 : $245-249$.

Kangawa, K., N. Minamino, N. Chino, S. Sakakibara, and H. Matsuo (1981) The complete amino acid sequence of $\alpha$-neoendorphin. Biochem. Biophys. Res. Commun. 99: 871-878.

Kilpatrick, D. L., A. Wahlstrom, H. W. Lahm, R. Blacher, and S. Udenfriend (1982) Rimophin, a unique, naturally occurring [Leu]enkaphalin-containing peptide found in association with dynorphin and $\alpha$-neo-endorphin. Proc. Natl. Acad. Sci. U. S. A. 79: 6480-6483.

Kitamura, K., N. Minamino, Y. Hayashi, K. Kangawa, and H. Matsuo (1982) Regional distribution of $\beta$-neo-endorphin in rat brain and pituitary. Biochem. Biophys. Res. Commun. 109: 966-974.

Land, H., G. Schutz, H. Schmale, and D. Richter (1982) Nucleotide sequence of cloned cDNA encoding bovine arginine vasopressin-neurophysin II precursor. Nature 295: 299-303.

Lowry, O. H., N. J. Rosebrough, A. L. Farr, and R. J. Randall (1951) Protein measurement with the Folin phenol reagent. J. Binl. Chem. 19.3: 265-275.

Minamino, N., K. Kangawa, A. Fukuda, H. Matsuo, and M. Igarashi (1980) A new opioid octapeptide related to dynorphin from procine hypothalamus. Biochem. Biophys. Res. Commun. 95: 1475-1481.

Minamino, N., K. Kangawa, N. Chino, S. Sakakibara, and H. Matsuo (1981) $\beta$-Neo-endorphin, a new hypothalamic "big" leu-enkephalin of porcine origin: Its purification and the complete amino acid sequence. Biochem. Biophys. Res. Commun. 99: 864-870.

Seizinger, B. R., V. Hollt, and A. Herz (1981) Immunoreactive dynorphin in the rat adenohypophysis consists exclusively of 6000-dalton species. Biochem. Biophys. Res. Commun. 103: $256-263$.

Weber, E., C. J. Evans, and J. D. Barchas (1982a) Predominance of the amino-terminal octapeptide fragment of dynorphin in rat brain regions. Nature 299: 77-79.

Weber, E., C. J. Evans, J. K. Chang, and J. D. Barchas (1982b) Brain distribution of $\alpha$-neo-endorphin and $\beta$-neo-endorphin: Evidence for regional processing differences. Biochem. Biophys. Res. Commun. 108: 81-88. 